\title{
Adventure tourism and adventure sports injury: The New Zealand experience
}

\author{
Tim A Bentley ${ }^{\mathrm{a}}{ }^{*}$, Stephen J Page ${ }^{\mathrm{b}}$, Keith A Macky ${ }^{\mathrm{a}}$ \\ ${ }^{a}$ Department of Management and International Business, Massey University at \\ Albany, Private Bag 102904 NSMC, Auckland, New Zealand \\ ${ }^{\mathrm{b}}$ Department of Marketing, University of Stirling, Stirling, Scotland FK99 4LA, UK
}

Research article re-submitted to the journal: Applied Ergonomics 


\begin{abstract}
The primary aims of this study were to establish a client injury baseline for the New Zealand adventure tourism and adventure sport sector, and to examine patterns and trends in claims for injury during participation in adventure activities. Content analysis of narrative text data for compensated injuries occurring in a place for recreation and sport over a 12-month period produced over 15,000 cases involving adventure tourism and adventure sport. As found in previous studies in New Zealand, highest claims counts were observed for activities that are often undertaken independently, rather than commercially. Horse riding, tramping, surfing and mountain biking were found to have highest claims counts, while hang gliding/paragliding/parasailing and jet boating injuries had highest claims costs, suggesting greatest injury severity. Highest claims incidence was observed for horse riding, with female claimants over-represented for this activity. Younger male claimants comprised the largest proportion of adventure injuries, and falls were the most common injury mechanism.
\end{abstract}

Keywords: Adventure tourism; Adventure sport; Unintentional injury; Injury compensation claims; Injury epidemiology 


\section{Introduction}

Adventure tourism is a rapidly expanding sector of the tourism industry internationally. New Zealand is internationally recognised as a country where adventure tourism and adventure sports are undertaken by a large proportion of the resident and visitor population. While the risks associated with adventure tourism and adventure sport activity are increasingly highlighted in media reports of fatalities and serious injuries to overseas and domestic recreationalists in New Zealand and elsewhere (Wilks and Atherton, 1994), relatively little research has been conducted in this area. One important reason for the lack of serious interest in this phenomena by researchers, governments and the tourism industry, is that the extent of the tourism health and safety problem is unknown in most countries due to the absence of injury surveillance and/or any one body reliably collating and reporting national or industry injury statistics.

Millington et al (2001:67) define adventure travel as 'a leisure activity that takes place in an unusual, exotic, remote or wilderness destination. It tends to be associated with high levels of activity by the participant, most of it outdoors. Adventure travellers expect to experience various levels of risk, excitement and tranquillity, and be personally tested. In particular they are explorers of unspoilt, exotic parts of the planet and also seek personal challenges.' From this definition it is apparent that the adventure recreationalist faces a variety of potential risk factors, including interacting factors associated with unfamiliar environments, remote locations, unfamiliar activities, risk-taking, and challenge. 
Recent work by these and other authors (e.g. Ryan, 2003; Wilks and Davis, 2000) has begun to explore the extent and nature of these risks and the ability of the adventure tourism sector to control injury risk to clients of their activities through risk management (see Swarbrooke et al, 2003 for a good account of approaches to risk management in adventure tourism). Early studies into adventure tourism safety in New Zealand provided evidence that activities such as white water rafting, scenic flights and mountain recreation, present significant risk of injury and loss of life to clients (e.g. Greenaway, 1996; Hall \& McArthur, 1991; Johnson, 1989; McLaughlan, 1995; Page \& Meyer, 1996). Building upon this work, Bentley et al. (2001a), from an analysis of overseas visitor hospitalisation data in New Zealand for the 15-year period, 1982-1996, identified 1027 overseas visitor hospitalisations where the injury was the result of adventure tourism and adventure sport activity. This figure represented $17 \%$ of all overseas visitor injuries and $22 \%$ of fatalities during this period, and an injury-incidence rate of approximately eight hospitalised injuries per 100,000 overseas visitors (this may be compared to a motor vehicle traffic accident rate of approximately 12 hospitalised injuries per 100,000 visitors). Recreationalists engaged in unguided, independent adventure activities, notably skiing and mountaineering, were most frequently injured or killed as a result of their activity, while highest counts of commercial adventure tourism injuries were observed for horse riding and cycling.

Two surveys of New Zealand adventure tourism operators carried out during the past six-years have produced data that supports the findings of the hospitalisations study outlined above as they relate to the commercial sector, with horse riding and mountain biking activities having relatively large injury counts and incidence rates. (Bentley et 
al., 2001b; Bentley and Page, 2006). These studies indicated that slips, trips and falls on the level and falls from a height were the major injury mechanisms for adventure activities, while operators identified a range of risk factors for adventure tourism injuries, including unfamiliar wilderness and marine environments and underfoot hazards such as slippery walking conditions.

The present study builds on this earlier research, and in particular seeks to establish up-to-date client injury baseline data for New Zealand adventure tourism and adventure sport, and to examine patterns and trends in claims for injury during participation in adventure activities. The data will provide a platform for further more detailed studies examining key risk factors for high-risk activity sectors and environments, and the risk management practices of adventure tourism operators.

\section{Methodology}

Compensation claims data for adventure tourism and adventure sport-related injuries to adult (16 years and over) New Zealand residents occurring during the 12-month period, July 2003 to June 2004, were extracted from the Accident Compensation Corporation's (ACC) database for injuries occurring at a place for sport or recreation. The initial dataset of approximately 40,000 cases was contained in a single Excel data file. The involvement or otherwise of adventure and recreational tourism activity was determined by content analysis of the one-line narrative descriptions of incident circumstances provided for each case, with non-adventure cases removed from the dataset, and adventure activities coded under one of 27 categories of adventure tourism/sports. Unfortunately, many cases contained insufficient information in the narrative to determine adventure involvement, stating only that the claimant had 
‘fallen off a rock', was ‘walking along a beach’ or ‘was riding my bike’ for example, meaning many tramping, mountaineering, rock climbing, mountain biking and marine activity cases may have been omitted from the analysis erroneously. It should be noted, therefore, that the final dataset of 15,648 cases is likely to underestimate the total number of compensated adventure and recreation-related injuries during the period of the analysis.

For each of these cases the following variables were available for analysis: age, gender, ethnicity of the claimant; region where the incident occurred; month of incident; adventure activity; injury initiating event; body part injured; injury diagnosis and cost of claim. The majority of these variables were categorical in nature, the exceptions being age and cost of claim, for which interval and ordinal (age and cost groups) variables were provided. Once coded, the data were transferred from Excel to SPPS for Windows V.13. Descriptive analyses were undertaken for each of the variables, including cross-tabulation, and non-parametric inferential statistics (including Chi Square and Kruskal-Wallis tests) applied where differences and associations between categories and variables were examined.

Claims incident rates were calculated where suitable participation and population data was available. Denominator data were 2005 population figures provided by Statistics New Zealand and New Zealand adult participation in sport and active leisure, as derived by Sport and Recreation New Zealand (SPARC) from sample surveys conducted during 2000. It is noted, therefore, that participation data are only indicative of New Zealander participation in adventure tourism and adventure sports activities. 


\section{Results}

\subsection{Demographical distribution}

A total of 15,648 adventure tourism and adventure sports cases were identified from the database. Claimants had a mean age of 36.4 years $(S D=14)$. Table 1 shows the distribution of claimants by age group and median and total costs of claims (as best available proxy for injury severity) for each age range.

Table 1 about here

The age groups differed significantly in the number of claims for adventure tourism and adventure sport injuries $\left(\chi^{2}(6)=5904.8, p=.000\right)$. The largest proportion of claims was incurred by claimants in the 21-40 age range, whose claims comprised $50 \%$ of all claims. However, claims were most expensive, and therefore injuries potentially most severe, in the 60-plus age range. A Kruskal-Wallis test using the Monte Carlo method showed that the cost of claims for adventure tourism and sports injuries is related to the age of the claimant $(H(6)=94.9, p=.000)$. As Table 1 indicates, the median cost of claims increases through to the 41-50 age group, plateaus and then increases again for the 62-70 and $>70$ age groups. Jonckheere's test supports this observed trend in the data of claims costs increasing with claimant age ( $Z=9.5$, $p=.000)$.

As expected, males (63.3\%) made significantly more claims than females (36.7\%) $\left(\chi^{2}(1)=1106.9, p=.000\right)$, although gender of claimant distributions varied considerably across the various activities (see 3.3 below). The claim rate for male claimants was 491.1 per 100,000 people, compared to a rate of 275.8 for females. 
The median cost of claims was lower for male (NZ\$93.7) than for female (NZ\$106.4) claimants. Male and female claimants had almost identical mean ages (males $=36.4$; females $=36.2)$. Females in the youngest (16-20) and oldest (61-70 and >70) age groups were responsible for a relatively high proportion of claims, incurring at least $40 \%$ of adventure injuries in these age ranges. Claimants were predominantly New Zealand European (76\%), while just 6\% of claimants were New Zealand Maori, 1.4\% Asian and 1\% Pacific Islanders.

\subsection{Distribution of claims and cost by activity}

Table 2 shows the major activity categories for adventure tourism and adventure sports injuries in New Zealand for the period of the analysis, along with an analysis of claims costs by activity.

Table 2 about here

Land-based activities comprised 59\% of all cases, 38\% involved water-borne activities and just 1\% cases were aviation-based. More than half of all adventure injuries were incurred during participation in just four activities: horse riding, tramping, mountain biking and surfing. Horse riding had notably higher claims incidence rates than for other activities where incidence rates could be calculated, being almost two-times greater than that for mountain biking. Relatively low incidence rates were found for skiing and fishing, two of the most popular New Zealand recreational activities. 
A Kruskal-Wallis test using the Monte Carlo method showed that the cost of claims was related to the activity of the claimant $(H(24)=298.7, p=.000)$. Hang gliding paragliding/parasailing participants incurred notably greater claims costs, with some $36.1 \%$ of claims for this activity resulting in compensation over NZ $\$ 1000$, compared to just $10 \%$ of cases across all activities. Relatively low costs of claims were associated with diving, bungee jumping and jet boating activities.

Male claimants had notably more claims for the majority of activities, the major exception being horse riding (78.5\% of claimants were female). A relatively even distribution of claims by gender was found for white water rafting, tramping, bungee jumping, abseiling, jet boating and skiing. Male claimants most notably dominated claims for hunting (92.6\% of claims), hang gliding/paragliding/parasailing (89.4\%), fishing (84.5\%), surfing (82.7\%), mountain biking (80.7\%) and snowboarding (72.6\%).

A number of activities had notably lower mean age of injured participant, including snowboarding (mean age=24.9 years, compared to an overall mean age of 36.4), wakeboarding (28 years) and bungee jumping (29.1 years). Older claimants tended to be injured while fishing (46 years), tramping (44 years), jet boating (44 years) and hang gliding (42 years).

Adventure tourism and adventure sports injuries clustered around known adventure tourism regions and population centres. Thus, $16 \%$ of adventure tourism-related injuries occurred in the Auckland area, 13\% in Canterbury, 13\% in the Waikato and $10 \%$ in the Bay of Plenty. A further $9 \%$ of cases were from Otago, the region within 
which the 'world capital for adventure tourism', Queenstown, is situated. Activities tended to group in specific regional areas of New Zealand, with mountain biking injuries most frequently incurred in the Central North Island adventure centres such as Rotorua and in the Sound Island adventure capital of Queenstown. Similarly, snow sports injuries were predominantly based around the Southern Alps and Central North Island regions.

The temporal distribution of claims reflected the seasonal nature of New Zealand adventure tourism and sports, with some $60 \%$ of injuries incurred during the summer months, December-April. Figure 1 shows the distribution of the top four frequency activities by month of injury occurrence. The distribution of activities across the summer season is highlighted, while surfing injuries occur in significant quantities during the January holiday period.

Figure 1 about here

\subsection{Mechanism of injury and injury type}

The large majority of adventure tourism injuries resulted from falls, including overbalancing, slipping and tripping (71\%), often from a height and while moving at speed. The activities for which falls were most common included horse riding, mountain biking, snowboarding and tramping. Other categories of injury mechanism included lifting and/or carrying (7\%) and colliding with something (4\%). Lifting and carrying injuries most frequently occurred during kayaking, tramping, surfing and waterskiing. Many cases involved the claimant being injured while lifting or moving a pack or piece of equipment, often a kayak. 
The most frequently injured body parts for adventure tourism and adventure sports claims were the shoulder (11\%), knee (10\%), lower back/spine (10\%) and ankle (7\%). Unsurprisingly, injuries to multiple locations resulted in largest compensation amounts, reflecting greatest injury severity. Other high-cost injuries were to the neck/vertebrae, head and eye. Major body part injury areas for the four highest frequency activities are shown in Figure 2.

Figure 2 about here

Each of the top four activities have distinct injury patterns, with horse riding claimants suffering injuries to the lower back and spine, while trampers most frequently injured the ankle and knee. Mountain biking injuries were most commonly to the shoulder, and surfing injuries were concentrated on the upper limb, and in particular the neck and shoulder. Surfers also received a relatively large proportion of injuries to the face, presumably through being struck by surf boards or dumped on the seabed by a wave.

The major type of injury diagnosis was soft tissue injury (stains and sprains), comprising $58.7 \%$ of cases. Soft tissue injuries were most frequently located at the lower limb (mainly the knee and ankle), upper limb (mainly the shoulder and neck) and lower back. Fractures and dislocations, suggesting a more severe injury outcome, were the injury type in $13 \%$ of cases, and were most frequently located at the upper limb, specifically shoulder, hand wrist and fingers. A further $13 \%$ of cases involved lacerations. 


\section{Discussion and Conclusions}

These findings indicate a significant adventure tourism and adventure sports problem in New Zealand in terms of participant injury, with more than 15,000 domestic adventure injury cases being serious enough to require compensation. This figure underestimates the true quantity of injuries as many cases will not have been captured by ACC's sport and recreation database for various reasons, and many that were included on the database had insufficient information from which to code them as involving adventure activity. Moreover, these figures exclude the large number of injuries involving overseas visitors to New Zealand each year (Bentley et al., 2001a). Adventure tourism and adventure sports-related claims comprised a total financial burden of over \$15 million over the one-year period of the analysis. Some activity sectors, notably hang gliding, paragliding and parasailing, were associated with notably higher compensation costs, suggesting injuries resulting from these activities tend to be very serious events.

As found in previous studies by these authors (e.g. Bentley et al., 2001a; Bentley et al., 2001c; Bentley and Page, 2006), adventure activities that are predominantly undertaken independently, rather than commercially, were associated with a large proportion of incidents, in particular tramping, surfing, mountaineering, mountain biking, fishing and waterskiing. Mountaineering and tramping has also been associated with relatively large numbers of fatalities involving overseas visitors who may be unfamiliar with New Zealand terrain and changeable weather conditions (Bentley et al., 2001c). This suggests the need for improved information and safety messages for recreationalists, ideally situated at adventure locations and places where people participating in these activities travel and are accommodated. 
Adventure activities that are not currently covered by regulation or codes of practice, including mountain biking and horse riding, featured most frequently in injury compensation data, had highest incidence rates (where participation data could be estimated) and often resulted in relatively serious injury. These findings suggest the need for some level of regulatory intervention in the commercial sector for these activities (Northey, 2003), with the aim of producing improved risk management practice among operators, along with measures to improve the safety of individual recreationalists participating in these activities.

The large number of claims for injuries during activities that are usually offered commercially is also of concern. These include horse riding, white water rafting, quad biking and jet boating; activities that have been associated with fatalities involving overseas visitors and New Zealand residents in recent years (e.g. Bentley et al., 2001c). Diving, an activity that is commonly led by commercial organisations, resulted in particularly high numbers of claims. Further research will examine the risk management activities of operators in these activity sectors.

Falls were found to be the major injury mechanism in both studies, suggesting attention of injury prevention efforts should focus on risk factors for slips, trips and falls and falls from a height as they relate to each activity sector. For example, tramping operators should focus on underfoot conditions on their walking tracks and the footwear used by their clients. Activities undertaken at speed, including mountain biking and skiing, should also consider secondary safety issues in the design of personal protective equipment that may reduce injuries at the most vulnerable body areas. Indeed, specific areas of injury were identified for some high-injury activities, 
including the shoulder for mountain biking and surfing, knee and ankle injuries for tramping and mountaineering and the lower back for horse riding. This information could be used in the development of interventions, such as personal protective equipment, to reduce the extent of injury for these activities.

Claims were incurred in greatest number and incidence by male participants. Injury prevention messages and other interventions to reduce adventure injury risk should focus on younger male participants of activities such as mountain biking, surfing and snowboarding, with the exception being horse riding, for which female participants dominate (Northey, 2003). Older males should be the target of messages and other interventions relating to activities such as fishing, tramping and hang gliding.

Limitations of the findings of the data analysis for adventure tourism and adventure sports related-claims include the inability to identify a large number of cases that may have been adventure-related from the available data. The methodology employed in the selection of cases, however, ensured cases where the involvement of adventure activity could not be clearly determined were not included in the dataset for analysis. A further problem was the absence of reliable denominator data from which to determine incidence rates for the entire range of adventure activities considered in the study. Despite these shortcomings, the data provides a useful baseline picture of the adventure tourism and sports injury situation in New Zealand.

Future research and intervention will focus on activities identified here and in earlier research as carrying greatest client injury risk in terms of injury counts and incidence rates, including horse riding, tramping, surfing, kayaking, diving and mountain 
biking. In addition, activities where injury severity appears to be greatest, notably hang gliding, paragliding, parasailing and jet boating, need to be addressed through research. Research will also examine in detail the problem of falls in adventure recreation. In terms of commercial adventure tourism management, it is crucial to gather an improved understanding of operators' risk management practices and to develop best practice standards for improving client safety across the New Zealand adventure tourism and adventure sports industry.

\section{References}

Bentley, T. A. Meyer, D. Page, S. J. and Chalmers, D. (2001a). Recreational tourism injuries among visitors to New Zealand: an exploratory analysis using hospital discharge data. Tourism Management, 22, 373-381.

Bentley, T. A., Page, S. J. (2006). Tourist injury. In J. Wilks, D. Pendergast and P. Leggat (Eds.) Tourism in Turbulent Times. Towards Safe Experiences for Visitors, pp:155-170. Amsterdam: Elsevier.

Bentley, T. A., Page, S. J. and Laird, I. (2001b). Accidents in the New Zealand adventure tourism industry, Safety Science, 38 (1), 31-48.

Bentley, T., Page, S.J., Meyer, D., Chalmers, D. and Laird, I. (2001c). How safe is adventure tourism in New Zealand ? An exploratory analysis. Applied Ergonomics, 32, 327-338. 
Greenaway, R. (1996). Thrilling not killing: Managing the risk tourism business. Management 1996 (May): 46-49.

Hall, C. and McArthur, S. (1991). Commercial white water rafting in Australia. Australian Journal of Leisure and Recreation, 1, 25-30.

Johnson, M (1989). Accidents in mountain recreation: The experiences of international and domestic visitors in New Zealand. GeoJournal, 19, 323-328.

McLaughlan, M. (1995). White water death: Why is the Shotover New Zealand's most lethal river ? North and South (December): 70-81.

Millington, K., Locke, T. and Locke, A. (2001). Occasional studies: adventure travel. Travel and Tourism Analyst, 4, 65-97.

Northey, G. (2003). Equestrain injuries in New Zealand, 1993-2001: Knowledge and experience. The New Zealand Medical Journal, 116, 1-8.

Page, S.J. and Meyer, D. (1996). Tourism accidents: An exploratory analysis. Annals of Tourism Research, 23, 666-690.

Ryan, C. (2003). Risk acceptance in adventure tourism - paradox and content, in J. Wilks and S. J. Page (eds) Managing Tourist Health and Safety in the New Millennium. Oxford: Pergamon, 55-66. 
Swarbrooke, J., Beard, C., Leckie, S. and Pomfret, G. (2003). Adventure Tourism: The New Frontier. Oxford: Butterworth Heinemann.

Wilks, J. and Atherton, T. (1994). Health and safety in marine tourism: A social, medical and legal appraisal. Journal of Tourism Studies, 5, 2-16.

Wilks, J. and Davis, R. (2000). Risk management for scuba diving operators on Australia’s Great Barrier Reef. Tourism Management, 21, 591-599.

\section{Acknowledgement}

This study was completed with the assistance of the Accident Compensation

Corporation (ACC) who provided the raw data. Views and conclusions in this article are those of the authors and may not reflect those of ACC.

Word count: 3644 


\section{Adventure tourism and adventure sport injury: The New Zealand experience}

Bentley, T.A., Page, S.J. and Macky, K.A.

\section{Captions}




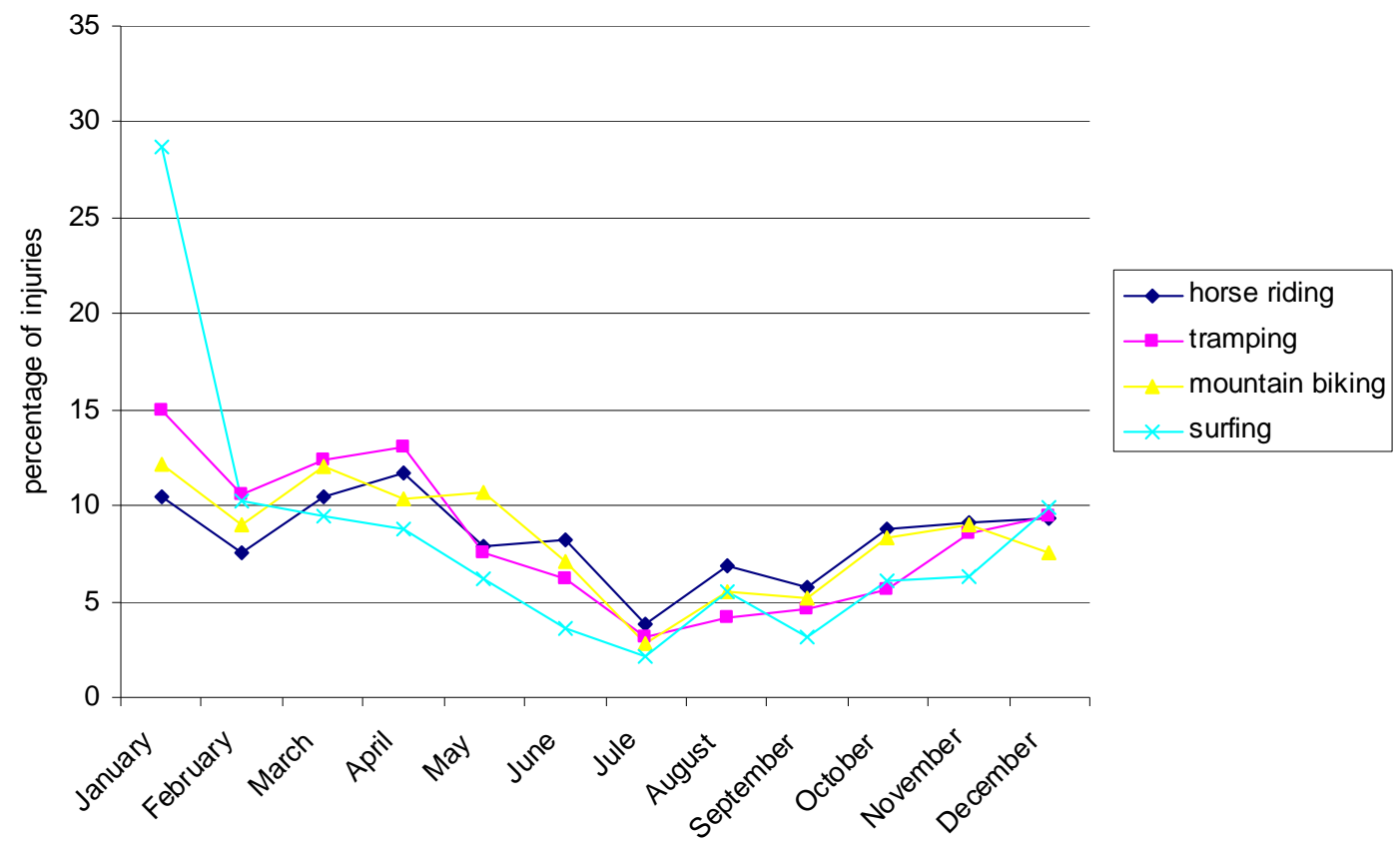

Figure 1. Distribution of top four claims count activities by month 


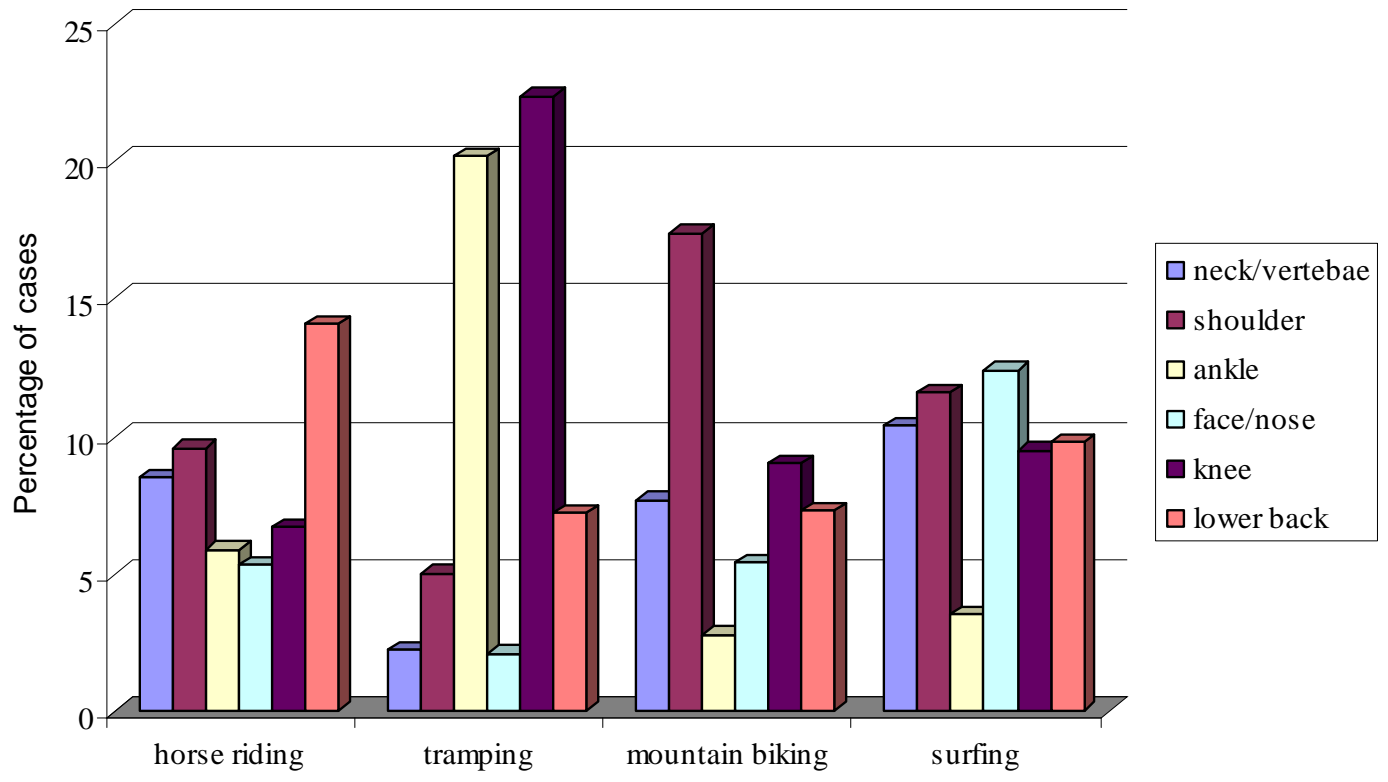

Figure 2. Distribution of major body parts injured by activity 
Table 1. Distribution and cost of adventure tourism claims by age

\begin{tabular}{l|rrrrrl}
\hline Age group & $n$ & $\%$ & $\begin{array}{l}\text { Median cost } \\
\text { of claim NZ\$ }\end{array}$ & Q1 & Q3 & $\begin{array}{l}\text { Total cost of } \\
\text { claims NZ\$* }\end{array}$ \\
\hline $16-20$ & 2081 & 13 & 77.7 & 33.2 & 223.1 & 862,424 \\
$21-30$ & 4202 & 27 & 86.9 & 33.7 & 242.8 & $2,848,997$ \\
$31-40$ & 3613 & 23 & 101.3 & 44.4 & 285.9 & $3,222,477$ \\
$41-50$ & 3107 & 20 & 110.2 & 46.2 & 334.8 & $5,198,039$ \\
$51-60$ & 1728 & 11 & 108.2 & 46.2 & 371.5 & $2,788,321$ \\
$61-70$ & 657 & 4 & 119.8 & 47.1 & 314.3 & 530,043 \\
$>70$ & 260 & 2 & 147.2 & 55.9 & 341.8 & 189,854 \\
\hline Total & $15648 *$ & 100 & 98.6 & 42.5 & 285.9 & $15,640,155$ \\
\hline
\end{tabular}

*note: these figures exclude the cost of cases $(n=1296)$ that no cost data was provided in the dataset 
Table 2. Distribution and cost of claims by activity

\begin{tabular}{|c|c|c|c|c|c|c|}
\hline Activity & $n$ & $\%$ & $\begin{array}{l}\text { Claims } \\
\text { incidence } \\
\text { rate per } 1000 \\
\text { participants* }\end{array}$ & $\begin{array}{l}\text { Median } \\
\text { cost per } \\
\text { case } \\
(\mathrm{NZ \$})\end{array}$ & Q1 & Q3 \\
\hline Horse riding & 2681 & 17.0 & 20.1 & 113.9 & 46.2 & 445.9 \\
\hline Tramping & 2113 & 13.4 & 6.5 & 108.9 & 46.1 & 287.3 \\
\hline Surfing & 1954 & 12.4 & 9.7 & 84.3 & 33.7 & 193.3 \\
\hline Mountain biking & 1947 & 12.4 & 11.0 & 128.4 & 53.9 & 391.9 \\
\hline Fishing & 1336 & 8.5 & 2.0 & 60.5 & 33.1 & 160.7 \\
\hline Waterskiing & 1164 & 7.4 & & 106.2 & 33.8 & 282.6 \\
\hline Snowboarding & 745 & 4.7 & & 104.6 & 33.2 & 334.2 \\
\hline Kayaking/canoeing & 680 & 4.3 & & 101.3 & 40.7 & 232.0 \\
\hline Hunting & 485 & 3.1 & & 85.0 & 33.2 & 292.2 \\
\hline Diving/snorkelling & 445 & 2.8 & & 64.7 & 25.8 & 177.0 \\
\hline Wakeboarding/sea biscuit & 243 & 1.5 & & 74.3 & 26.9 & 236.2 \\
\hline Rock climbing & 235 & 1.5 & & 101.3 & 46.0 & 219.6 \\
\hline Wind surfing/kite surfing & 223 & 1.4 & & 104.1 & 47.1 & 289.1 \\
\hline BMX biking & 216 & 1.4 & & 114.4 & 53.1 & 492.8 \\
\hline Mountaineering & 212 & 1.3 & & 101.3 & 45.3 & 304.5 \\
\hline Luge & 171 & 1.1 & & 96.9 & 46.2 & 240.6 \\
\hline White water rafting & 117 & 0.7 & & 84.3 & 33.7 & 188.6 \\
\hline ATV/quad bike & 111 & 0.7 & & 105.3 & 54.6 & 349.0 \\
\hline Jet skiing & 111 & 0.7 & & 106.2 & 48.5 & 271.3 \\
\hline Skiing & 95 & 0.6 & 0.6 & 146.0 & 64.9 & 649.8 \\
\hline Skydiving & 83 & 0.5 & & 105.1 & 33.7 & 529.8 \\
\hline Jet boating & 75 & 0.5 & & 91.0 & 33.5 & 476.0 \\
\hline Bungee jumping & 57 & 0.4 & & 57.3 & 23.1 & 108.7 \\
\hline $\begin{array}{l}\text { Hang gliding/paragliding/ } \\
\text { parasailing }\end{array}$ & 47 & 0.3 & & 664.1 & 67.6 & 2787.1 \\
\hline Other & 102 & 0.7 & & & & \\
\hline Total & 15648 & 100 & & 98.6 & 42.5 & 285.9 \\
\hline
\end{tabular}

*Based on SPARC Aotearoa estimates of participation in sport and active leisure by NZ adults 
